Research Article

\title{
Geographical Characterization of Tunisian Olive Tree Leaves (cv. Chemlali) Using HPLC-ESI-TOF and IT/MS Fingerprinting with Hierarchical Cluster Analysis
}

\author{
Amani Taamalli $\mathbb{D}^{1},{ }^{1}$ David Arráez Román, ${ }^{2,3}$ Ana María Gómez Caravaca, ${ }^{2,3}$ \\ Mokhtar Zarrouk, ${ }^{1}$ and Antonio Segura Carretero $\mathbb{D}^{2,3}$ \\ ${ }^{1}$ Laboratoire de Biotechnologie de l'Olivier, Centre de Biotechnologie de Borj-Cedria, Hammam-Lif, Tunisia \\ ${ }^{2}$ Center of Research and Development of Functional Food, Health Science Technological Park, Avda. del Conocimiento s/n, \\ 18100 Granada, Spain \\ ${ }^{3}$ Department of Analytical Chemistry, Faculty of Sciences, University of Granada, 18071 Granada, Spain
}

Correspondence should be addressed to Amani Taamalli; taamalli_ameni@yahoo.fr

Received 29 October 2017; Revised 12 January 2018; Accepted 28 January 2018; Published 13 March 2018

Academic Editor: Antony C. Calokerinos

Copyright (c) 2018 Amani Taamalli et al. This is an open access article distributed under the Creative Commons Attribution License, which permits unrestricted use, distribution, and reproduction in any medium, provided the original work is properly cited.

\begin{abstract}
The olive plant has been extensively studied for its nutritional value, whereas its leaves have been specifically recognized as a processing by-product. Leaves are considered by-products of olive farming, representing a significant material arriving to the olive mill. They have been considered for centuries as an important herbal remedy in Mediterranean countries. Their beneficial properties are generally attributed to the presence of a range of phytochemicals such as secoiridoids, triterpenes, lignans, and flavonoids. With the aim to study the impact of geographical location on the phenolic compounds, Olea europaea leaves were handpicked from the Tunisian cultivar "Chemlali" from nine regions in the north, center, and south of Tunisia. The ground leaves were then extracted with methanol : water $80 \%(v / v)$ and analyzed by using high-performance liquid chromatography coupled to electrospray time of flight and ion trap mass spectrometry analyzers. A total of 38 compounds could be identified. Their contents showed significant variation among samples from different regions. Hierarchical cluster analysis was applied to highlight similarities in the phytochemical composition observed between the samples of different regions.
\end{abstract}

\section{Introduction}

Natural antioxidants present in the diet have evidenced the increase of the resistance toward oxidative damages, and they may have a substantial impact on human health [1]. Furthermore, the use of natural extracts from plants as functional ingredients in food, beverage, and cosmetic applications is receiving a great deal of attention among scientists, as well as among consumers and food manufacturers [2]. Recently, there has been a renewed interest in natural product research due to the failure of alternative drug discovery methods to deliver many lead compounds in key therapeutic areas such as immune suppression, antiinfectives, and metabolic diseases [3]. Despite competition from other drug discovery methods, natural products are still providing their fair share of new clinical candidates and drugs [3]. We can find several natural products as sources of new drugs that have been recently reviewed in literature [4-7].

The olive plant has been extensively studied for its nutritional value, whereas its leaves have been specifically recognized as a processing by-product [8]. Considered as byproducts of olive farming, olive tree leaves represent a significant material arriving to the olive mill [9]. They have been considered for centuries as an important herbal remedy in Mediterranean countries. Their positive effects on human health are multiple: antioxidant [10-16], hypoglycemic [17], antimicrobial [18], and anticancerous [19-22] among others. These properties are generally attributed to the presence of 


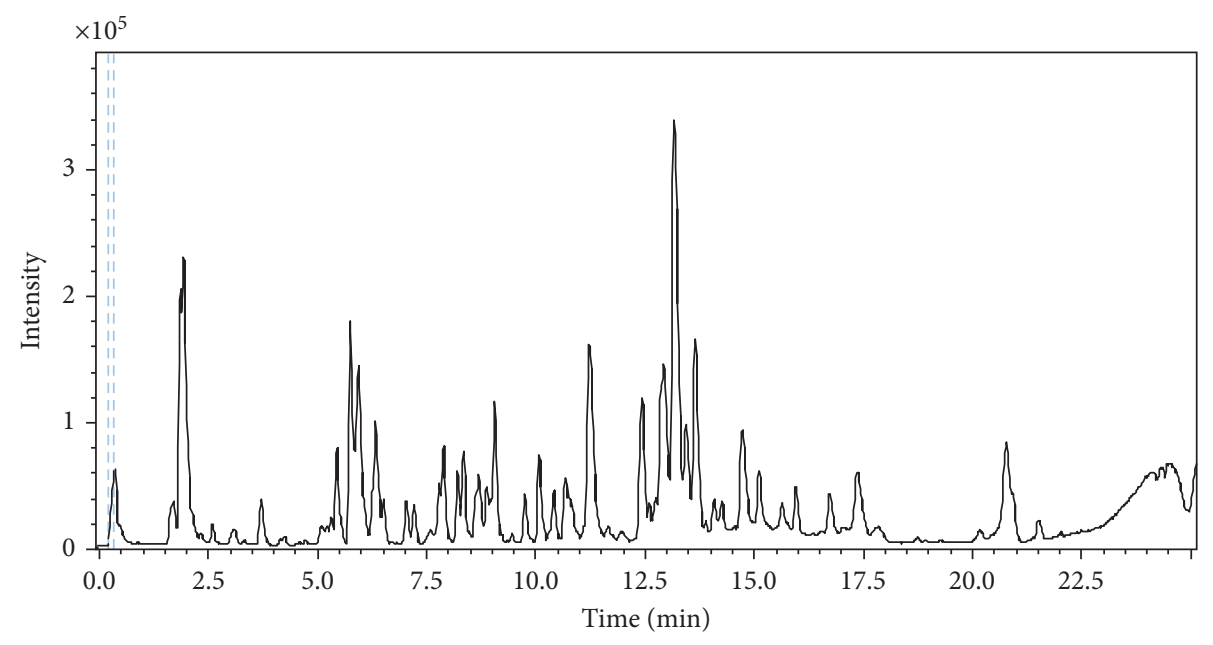

FIGURE 1: Base peak chromatogram of "Chemlali" olive leaf extract from Zaghouan region.

a range of compounds, such as secoiridoids, triterpenes, lignans, and flavonoids. It has been reported that byproducts can have a similar or even higher proportion of bioactive compounds than the usable parts of produce [23]. For instance, the characterization and quantification of bioactive compounds is one of the first steps to be taken in any evaluation of the putative contribution of the olive and its derivatives to human health [24] since the chemical composition of olive tree leaves varies depending on several conditions such as origin, proportion of branches on the tree, storage conditions, climatic conditions, moisture content, and degree of contamination with soil and oils [25]. Recently, the effects of abiotic and biotic factors on the phenolic composition in olive tree leaves have been reviewed in literature [26]. Biotic factors such as genotype, load bearing, leaves age, and fungi and bacteria attacks as well as abiotic factors such as hydric deficiency, salinity, fertilization, sampling time, geographical zone, and climatic conditions influence the contents of phenolic compounds [26]. Recent researches revealed the impact of the geographical location on the total phenolic composition of olive leaves [27-30]. However, the data on the variation of the individual phenolic compounds in olive leaves are scarce. According to our knowledge, this is the first study on the phenolic compounds in olive tree leaves from Tunisian cultivars according to the geographical region.

Considering the importance of phenolic compounds in olive leaves, their determination and the scarce literature related to their behavior according to geographical origin, the aim of this study was to explore the phenolic composition of the leaves from the Tunisian olive cultivar "Chemlali" from different localities. This cultivar was chosen since it is widespread throughout Tunisia from the north to the south.

\section{Materials and Methods}

2.1. Sample Collection and Preparation of Extracts. Fresh olive leaves from the Tunisian "Chemlali" cultivar were obtained at the time of olive pruning from different regions from Tunisia (north, center, and south from coastal and mountainous areas) (available here). Leaves were dried at $25^{\circ} \mathrm{C}$, ground, and then $1 \mathrm{~g}$ of the obtained homogenized powder was dissolved in $10 \mathrm{~mL}$ of methanol : water $80 \%$ $(v / v)$, and the mixture was allowed to stand in the dark for $24 \mathrm{~h}$ [31]. The extract was centrifuged at $5000 \mathrm{~g}$ for $10 \mathrm{~min}$ at room temperature, and the supernatants were then filtered using a $0.45 \mu \mathrm{m}$ syringe filter to be analyzed by highperformance liquid chromatography (HPLC).

2.2. Chromatographic Separation of Phenolic Compounds. An Agilent 1200 HPLC system (Agilent Technologies, Waldbronn, Germany) equipped with a vacuum degasser, autosampler, a binary pump, and a DAD detector was used for the chromatographic determination. Phenolic compounds were separated by using an Agilent Eclipse Plus C18-column $(4.6 \times 150 \mathrm{~mm}, 1.8 \mathrm{~mm}$ particle size $)$ operating at $25^{\circ} \mathrm{C}$ and a flow rate of $0.8 \mathrm{~mL} / \mathrm{min}$. The mobile phases used were water with acetic acid (0.5\%) (phase A) and acetonitrile (phase B), and the solvent gradient changed according to the following conditions: 0 to $10 \mathrm{~min}, 5-30 \% \mathrm{~B} ; 10$ to $12 \mathrm{~min}$, $30-33 \% \mathrm{~B} ; 12$ to $17 \mathrm{~min}, 33-38 \% \mathrm{~B}$; 17 to $20 \mathrm{~min}, 38-50 \% \mathrm{~B}$; and 20 to $23 \mathrm{~min}, 50-95 \% \mathrm{~B}$. Finally, the B content was decreased to the initial conditions (5\%) in $2 \mathrm{~min}$, and the column reequilibrated for $10 \mathrm{~min}$. A volume of $10 \mathrm{~mL}$ of the extracts was injected. The separated compounds were monitored in sequence first with a diode-array detector (DAD) at 240 and $280 \mathrm{~nm}$ and then with a mass spectrometry (MS) detector.

2.3. Time of Flight and Ion Trap Mass Spectrometry Detection. The HPLC system was firstly coupled to a Bruker Daltonics micrOTOF mass spectrometer (Bruker Daltonics, Bremen, Germany) using an orthogonal electrospray interface. The mass spectrometer was operated in the negative ionization mode and acquired data in the mass range from $\mathrm{m} / z 50$ to 1000 with a spectra rate of $1 \mathrm{~Hz}$. The capillary was set at $+4 \mathrm{kV}$, the end plate offset at $-500 \mathrm{~V}$, the nebulizer gas 
TABLE 1: Identification data for the compounds detected in olive leaf extracts.

\begin{tabular}{|c|c|c|c|c|c|}
\hline$m / z[\mathrm{M}-\mathrm{H}]^{-}$ & $\mathrm{RT}(\min )$ & Formula & Compound & IT/MS ${ }^{2}$ fragments & Class \\
\hline 191.0561 & 2.0 & $\mathrm{C}_{7} \mathrm{H}_{12} \mathrm{O}_{6}$ & Quinic acid & 103 & Other polar compounds \\
\hline 315.1085 & 5.8 & $\mathrm{C}_{14} \mathrm{H}_{20} \mathrm{O}_{8}$ & Hydroxytyrosol-hexose & 123,153 & Simple phenols \\
\hline 153.0557 & 6.6 & $\mathrm{C}_{8} \mathrm{H}_{10} \mathrm{O}_{3}$ & Hydroxytyrosol & 123 & Simple phenols \\
\hline 299.1136 & 7.0 & $\mathrm{C}_{14} \mathrm{H}_{20} \mathrm{O}_{7}$ & Tyrosol glucoside & & Simple phenols \\
\hline 403.1246 & 7.7 & $\mathrm{C}_{17} \mathrm{H}_{24} \mathrm{O}_{11}$ & Elenolic acid glucoside isomer 1 & & Secoiridoids and related compounds \\
\hline 389.1089 & 7.8 & $\mathrm{C}_{16} \mathrm{H}_{22} \mathrm{O}_{11}$ & Secologanoside & $183,209,227$ & Secoiridoids and related compounds \\
\hline 353.0878 & 7.9 & $\mathrm{C}_{16} \mathrm{H}_{18} \mathrm{O}_{9}$ & Caffeoylquinic acid isomer 1 & 191 & Other polar compounds \\
\hline 403.1246 & 8.3 & $\mathrm{C}_{17} \mathrm{H}_{24} \mathrm{O}_{11}$ & Elenolic acid glucoside isomer 2 & & Secoiridoids and related compounds \\
\hline 305.0667 & 8.7 & $\mathrm{C}_{15} \mathrm{H}_{14} \mathrm{O}_{7}$ & Gallocatechin & 225 & Flavanol \\
\hline 401.1453 & 8.7 & $\mathrm{C}_{18} \mathrm{H}_{26} \mathrm{O}_{10}$ & Benzyl alcohol hexose-pentose & 161 & Other polar compounds \\
\hline 403.1246 & 8.9 & $\mathrm{C}_{17} \mathrm{H}_{24} \mathrm{O}_{11}$ & Elenolic acid glucoside isomer 3 & $179,223,371$ & Secoiridoids and related compounds \\
\hline 353.1606 & 9.0 & $\mathrm{C}_{16} \mathrm{H}_{18} \mathrm{O}_{9}$ & Caffeoylquinic acid isomer 2 & 191 & Other polar compounds \\
\hline 377.1453 & 9.1 & $\mathrm{C}_{16} \mathrm{H}_{26} \mathrm{O}_{10}$ & Oleuropein aglycon derivative & & Secoiridoids and related compounds \\
\hline 403.1246 & 9.8 & $\mathrm{C}_{17} \mathrm{H}_{24} \mathrm{O}_{11}$ & Elenolic acid glucoside isomer c & & $\begin{array}{l}\text { Secoiridoids and related compounds } \\
\text { related compounds }\end{array}$ \\
\hline 525.1614 & 10.5 & $\mathrm{C}_{24} \mathrm{H}_{30} \mathrm{O}_{13}$ & Demethyloleuropein & & Secoiridoids and related compounds \\
\hline 609.1461 & 10.7 & $\mathrm{C}_{27} \mathrm{H}_{30} \mathrm{O}_{16}$ & Rutin & 300 & Flavonol \\
\hline 593.1512 & 11.0 & $\mathrm{C}_{27} \mathrm{H}_{30} \mathrm{O}_{15}$ & Luteolin rutinoside & 285 & Flavone \\
\hline 623.2075 & 11.0 & $\mathrm{C}_{29} \mathrm{H}_{36} \mathrm{O}_{15}$ & Verbascoside & 461,315 & Secoiridoids and related compounds \\
\hline 447.0933 & 11.2 & $\mathrm{C}_{21} \mathrm{H}_{20} \mathrm{O}_{11}$ & Luteolin glucoside isomer 1 & 285 & Flavone \\
\hline 701.2298 & 11.6 & $\mathrm{C}_{31} \mathrm{H}_{42} \mathrm{O}_{18}$ & Oleuropein glucoside & $539,377,307$ & Secoiridoids and related compounds \\
\hline 607.1668 & 11.8 & $\mathrm{C}_{28} \mathrm{H}_{32} \mathrm{O}_{15}$ & Diosmin isomer 1 & 299 & Flavone \\
\hline 577.1563 & 11.7 & $\mathrm{C}_{27} \mathrm{H}_{30} \mathrm{O}_{14}$ & Apigenin rutinoside & 269 & Flavone \\
\hline 607.1668 & 12.1 & $\mathrm{C}_{28} \mathrm{H}_{32} \mathrm{O}_{15}$ & Diosmin isomer 2 & 299 & Flavone \\
\hline 303.051 & 12.2 & $\mathrm{C}_{15} \mathrm{H}_{12} \mathrm{O}_{7}$ & Taxifolin & & Flavanonol \\
\hline 431.0984 & 12.4 & $\mathrm{C}_{21} \mathrm{H}_{20} \mathrm{O}_{10}$ & Apigenin glucoside & 268 & Flavone \\
\hline 447.0933 & 12.4 & $\mathrm{C}_{21} \mathrm{H}_{20} \mathrm{O}_{11}$ & Luteolin glucoside isomer 2 & 285 & Flavone \\
\hline 461.1089 & 12.6 & $\mathrm{C}_{22} \mathrm{H}_{22} \mathrm{O}_{11}$ & Chrysoeriol glucoside & & Flavone \\
\hline 569.1876 & 12.9 & $\mathrm{C}_{26} \mathrm{H}_{34} \mathrm{O}_{14}$ & Methoxyoleuropein & $537,403,337$ & Secoiridoids and related compounds \\
\hline 539.1770 & 13.2 & $\mathrm{C}_{25} \mathrm{H}_{32} \mathrm{O}_{13}$ & Oleuropein isomer 1 & $275,377,307$ & Secoiridoids and related compounds \\
\hline 539.1770 & 13.4 & $\mathrm{C}_{25} \mathrm{H}_{32} \mathrm{O}_{13}$ & Oleuropein isomer 2 & $275,377,307$ & Secoiridoids and related compounds \\
\hline 539.177 & 13.6 & $\mathrm{C}_{25} \mathrm{H}_{32} \mathrm{O}_{13}$ & Oleuropein isomer 3 & $275,377,307$ & Secoiridoids and related compounds \\
\hline 523.1820 & 14.5 & $\mathrm{C}_{25} \mathrm{H}_{32} \mathrm{O}_{12}$ & Ligstroside & 291, 259 & Secoiridoids and related compounds \\
\hline 377.1242 & 14.7 & $\mathrm{C}_{19} \mathrm{H}_{22} \mathrm{O}_{8}$ & Oleuropein aglycon isomer 1 & & Secoiridoids and related compounds \\
\hline 285.0405 & 15.9 & $\mathrm{C}_{15} \mathrm{H}_{10} \mathrm{O}_{6}$ & Luteolin & 175,151 & Flavone \\
\hline 301.0354 & 16.2 & $\mathrm{C}_{15} \mathrm{H}_{10} \mathrm{O}_{7}$ & Quercetin & & Flavonol \\
\hline 377.1242 & 17.3 & $\mathrm{C}_{19} \mathrm{H}_{22} \mathrm{O}_{8}$ & Oleuropein aglycon isomer 2 & 275 & Secoiridoids and related compounds \\
\hline 269.0455 & 18.6 & $\mathrm{C}_{15} \mathrm{H}_{10} \mathrm{O}_{5}$ & Apigenin & 225,151 & Flavone \\
\hline 299.0561 & 19.2 & $\mathrm{C}_{16} \mathrm{H}_{12} \mathrm{O}_{6}$ & Diosmetin & & Flavone \\
\hline
\end{tabular}

at 2 bar, and the dry gas at $9 \mathrm{~L} / \mathrm{min}$ at $250^{\circ} \mathrm{C}$. The accurate mass data of the molecular ions were processed through the software data analysis and target analysis 4.0 (Bruker Daltonics). External mass spectrometer calibration was performed using a Cole-Parmer syringe pump (Vernon Hills, Illinois, USA) directly connected to the interface, equipped with a Hamilton syringe (Reno, Nevada, USA). The standard solution was injected at the beginning of the run, and all the spectra were calibrated prior to phenolic compounds' identification. Then, the same HPLC system was coupled to a Bruker Daltonics Esquire 2000 ion trap mass spectrometer (Bruker Daltonics, Bremen, Germany) equipped with an electrospray interface (Agilent Technologies, CA, USA) operating in the negative ionization mode. The ion trap scanned at the $50-1000 \mathrm{~m} / z$ range at $13000 \mu / \mathrm{s}$ during the separation and detection. The maximum accumulation time for the ion trap was set at $200 \mathrm{~ms}$, the target count at 20000 , and compound stability was set at $50 \%$. The optimum values of the ESI-MS parameters were as follows: capillary voltage, $+3.0 \mathrm{kV}$; drying gas temperature, $300^{\circ} \mathrm{C}$; drying gas flow, $7.0 \mathrm{~L} / \mathrm{min}$; and nebulizing gas pressure, $21.7 \mathrm{psi}$. The instrument was controlled by Esquire NT software from Bruker Daltonics. Peak identification was performed on the basis of their relative retention time values, TOF-MS and ITMS/MS data, comparison with authentic standard solutions, and using the information previously reported in the literature [32]. Limits of detection (LOD) and quantification (LOQ) were respectively as follow: 0.09 and $0.3 \mathrm{ppm}$ for hydroxytyrosol, 0.31 and $1.03 \mathrm{ppm}$ for tyrosol, 0.02 and $0.06 \mathrm{ppm}$ for luteolin, and 0.02 and $0.06 \mathrm{ppm}$ for apigenin.

2.4. Radical-Scavenging Capacity (RSC). The olive leaf samples were analyzed for their capacity to scavenge the stable $\mathrm{DPPH}^{\bullet}$ radical [33]. A volume of $3 \mathrm{~mL}$ of a freshly prepared DPPH solution $\left(10^{-4} \mathrm{M}\right.$ in methanol) was added to $0.5 \mathrm{~mL}$ of 
TABLe 2: Phenolic composition (in \% of total phenolics) of "Chemlali" olive leaves from different regions.

\begin{tabular}{|c|c|c|c|c|c|c|c|c|c|}
\hline & Gabes & Ghraiba & El Hajeb & Jelma & Kondar & Lamta & Sidi Bou Ali & Teboulba & Zaghouan \\
\hline Quinic acid & $6.96 \pm 0.05$ & $5.21 \pm 0.01$ & $65 \pm 0.45$ & $7.86 \pm 0.41$ & $7.82 \pm 0.51$ & $9.26 \pm 0.36$ & $8.83 \pm 0.79$ & $6.58 \pm 0.24$ & $7.55 \pm 1.02$ \\
\hline Hyty- & & & & $3.02 \pm$ & & & & & \\
\hline Hyty & 2 & 02 & 02 & $1.16 \pm$ & & 06 & 08 & 09 & 0.01 \\
\hline Ty-Gl & -0 & 11 & 07 & $0.82 \pm 0$ & & $0.00+0$ & 21 & & \\
\hline EA-Gl isomer 1 & nd & $0.58 \pm 0.03$ & nd & $1.39 \pm 0.01$ & & nq & nd & $0.70 \pm 0.02$ & $1.34 \pm 0.11$ \\
\hline Secologanoside & nd & $\begin{array}{c}15.78 \pm \\
0.21\end{array}$ & $9.73 \pm 0.29$ & $\begin{array}{c}18.27 \pm \\
0.87\end{array}$ & $\begin{array}{c}14.36 \pm \\
0.66\end{array}$ & $\begin{array}{c}15.32 \pm \\
0.81\end{array}$ & $9.72 \pm 0.57$ & $\begin{array}{c}12.77 \pm \\
0.78\end{array}$ & $\begin{array}{c}14.17 \pm \\
0.53\end{array}$ \\
\hline $\begin{array}{l}\text { Caffeoylquinic acid } \\
\text { isomer } 1\end{array}$ & $0.30 \pm 0.01$ & $0.40 \pm 0.08$ & $0.18 \pm 0.03$ & $0.60 \pm 0.1$ & $0.32 \pm 0.08$ & $0.82 \pm 0.06$ & $0.42 \pm 0.03$ & $0.38 \pm 0.02$ & $0.74 \pm 0.02$ \\
\hline somer 2 & nd & nd & nd & $0.95 \pm 0.13$ & nd & nd & nd & $0.07 \pm 0.01$ & $0.35 \pm 0.07$ \\
\hline Gall & $0.16 \pm 0.01$ & $2.58 \pm 0.12$ & $2.39 \pm 0.1$ & $2.54 \pm$ & $3.78 \pm 0.4$ & $8.89 \pm 0.3$ & $4.35 \pm 0.24$ & 2.39 & \\
\hline $\begin{array}{l}\text { Benzyl alcohol } \\
\text { hexose-pentose }\end{array}$ & $1.90 \pm 0.04$ & $0.70 \pm 0.02$ & $0.90 \pm 0.01$ & $0.54 \pm 0.11$ & $1.03 \pm 0.31$ & $1.23 \pm 0.27$ & $1.35 \pm 0.45$ & $1.26 \pm 0.2$ & $0.86 \pm 0.11$ \\
\hline EA- & $.13 \pm 0.03$ & $1.90 \pm 0.00$ & $1.44 \pm 0.01$ & $1.76 \pm 0.07$ & $2.49 \pm 0.38$ & $1.14 \pm 0.13$ & $1.77 \pm 0.47$ & $1.42 \pm 0.29$ & $1.70 \pm 0.19$ \\
\hline $\begin{array}{l}\text { Caffeoylquinic acid } \\
\text { isomer } 2\end{array}$ & nd & $0.20 \pm 0.01$ & $0.17 \pm 0.01$ & $0.24 \pm 0.01$ & $0.19 \pm 0.05$ & $0.33 \pm 0.01$ & $0.21 \pm 0.00$ & $0.13 \pm 0.02$ & $0.25 \pm 0.02$ \\
\hline $\begin{array}{l}\text { ein aglycon } \\
\text { e }\end{array}$ & $5.29 \pm 0.06$ & $7.96 \pm 0.03$ & $7.95 \pm 0.39$ & $6.83 \pm 0.13$ & $\begin{array}{c}10.42 \pm \\
0.81\end{array}$ & $\begin{array}{c}13.30 \pm \\
0.59\end{array}$ & $8.85 \pm 0.77$ & $7.42 \pm 0.94$ & $7.16 \pm 0.43$ \\
\hline amer 4 & nd & $2.98 \pm 0.14$ & $3.85 \pm 0.14$ & $2.51 \pm 0.02$ & $3.41 \pm$ & $0.29 \pm 0.07$ & $2.51 \pm 0.09$ & $1.36 \pm 0.15$ & $1.14 \pm 0.21$ \\
\hline pein & & & & & & & & & \\
\hline Rut & nd & & & 0.20 & & & & & \\
\hline & $\mathrm{nq}$ & & & $0.06 \pm 0$ & nq & & & & \\
\hline & nq & $\mathrm{nq}$ & $0.23 \pm 0.04$ & nq & $\mathrm{nq}$ & $\mathrm{nq}$ & $0.20 \pm 0.11$ & $1.38 \pm$ & 0.18 \\
\hline $\begin{array}{l}\text { Luteolin glucoside } \\
\text { isomer } 1\end{array}$ & $3.63 \pm 0.01$ & $2.50 \pm 0.03$ & $1.74 \pm 0.54$ & $1.79 \pm 0.32$ & $1.91 \pm 0.01$ & $2.53 \pm 0.14$ & $2.12 \pm 0.65$ & $1.48 \pm 0.24$ & $2.57 \pm 0.22$ \\
\hline & $0.37 \pm 0.02$ & $0.20 \pm 0.01$ & & $0.85 \pm 0.05$ & $0.02 \pm 0.01$ & $\mathrm{nq}$ & & & $0.57 \pm 0.6$ \\
\hline Diosmi & & & & $\mathrm{nq}$ & $\mathrm{n}$ & $\mathrm{nq}$ & 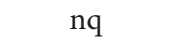 & & \\
\hline Apigenin rutinoside & $\mathrm{nq}$ & $0.04 \pm 0.01$ & $0.02 \pm 0.00$ & $0.02 \pm 0.01$ & $\begin{array}{r}0.04 \pm \\
0.012\end{array}$ & $0.15 \pm 0.01$ & $0.05 \pm 0.01$ & nq & $0.07 \pm 0.02$ \\
\hline & & & & $\mathrm{nq}$ & nq & $\mathrm{nq}$ & $\mathrm{nq}$ & nd & \\
\hline & 001 & & & 77 & & & & & \\
\hline & 0 & & & & & & & & \\
\hline n glucoside & $1.81 \pm 0.02$ & $1.21 \pm 0.13$ & & $0.75 \pm 0.15$ & $0.68 \pm 0.03$ & $1.08 \pm 0.12$ & $1.16 \pm 0.04$ & $\begin{array}{r}0.77 \pm \\
0.011\end{array}$ & $1.11 \pm 0.01$ \\
\hline Chryser & $47 \pm 0.03$ & $33 \pm 0.02$ & $.31 \pm 0.08$ & nd & $0.28 \pm 0.01$ & $0.34 \pm 0.03$ & $0.33 \pm 0.01$ & nq & $0.17 \pm 0.02$ \\
\hline Methoxyoleuropein & $\begin{array}{c}13.46 \pm \\
0.15\end{array}$ & $\begin{array}{c}11.27 \pm \\
0.23\end{array}$ & $9.54 \pm 0.12$ & $7.55 \pm 0.10$ & $\begin{array}{c}11.56 \pm \\
0.26\end{array}$ & $9.20 \pm 0.41$ & $12.01 \pm 0.10$ & $4.60 \pm 0.31$ & $7.52 \pm 0.16$ \\
\hline Oleuropein isomer 1 & $\begin{array}{c}25.39 \pm \\
1.68\end{array}$ & $\begin{array}{c}17.87 \pm \\
0.15\end{array}$ & $\begin{array}{c}20.25 \pm \\
0.15\end{array}$ & $\begin{array}{c}23.77 \pm \\
0.22\end{array}$ & $\begin{array}{c}15.76 \pm \\
0.35\end{array}$ & $\begin{array}{c}12.41 \pm \\
0.27\end{array}$ & $15.20 \pm 0.19$ & $\begin{array}{c}18.96 \pm \\
0.38\end{array}$ & $\begin{array}{c}22.87 \pm \\
0.47\end{array}$ \\
\hline Oleuropein isomer 2 & $5.31 \pm 0.31$ & & 0.37 & & $3.00 \pm 0.28$ & $1.15 \pm 0.10$ & & $4.25=$ & \\
\hline Oleuropein isomer 3 & $\begin{array}{c}11.55 \pm \\
0.45\end{array}$ & $6.62 \pm 0.11$ & $\begin{array}{c}12.03 \pm \\
0.14\end{array}$ & $9.79 \pm 0.07$ & $5.56 \pm 0.02$ & $2.24 \pm 0.15$ & $4.49 \pm 0.07$ & $\begin{array}{c}11.00 \pm \\
0.12\end{array}$ & $5.91 \pm 0.07$ \\
\hline Ii r ot & $0.55 \pm 0.02$ & $2.15 \pm 0.03$ & $2.00 \pm 0.10$ & $5.24 \pm 0.07$ & $1.57 \pm 0.12$ & $0.21 \pm 0.01$ & $0.90 \pm 0.02$ & $1.72 \pm 0.08$ & $6.83 \pm 0.03$ \\
\hline $\begin{array}{l}\text { Oleuropein aglycon } \\
\text { isomer } 1\end{array}$ & $6.84 \pm 0.05$ & $2.98 \pm 0.05$ & $2.77 \pm 0.04$ & nd & $4.10 \pm 0.09$ & $2.38 \pm 0.10$ & $3.73 \pm 0.14$ & $4.02 \pm 0.07$ & $3.58 \pm 0.04$ \\
\hline क्षात & $0.72 \pm 0.02$ & $1.60 \pm 0.01$ & $0.45 \pm 0.03$ & nd & $\begin{array}{r}2.19 \pm \\
0.015\end{array}$ & & $2.82 \pm 0.09$ & $\begin{array}{l}1.22 \pm \\
0.084\end{array}$ & $1.08 \pm 0.01$ \\
\hline & $0.01 \pm 0.00$ & $0.08 \pm 0.01$ & $0.06 \pm 0.01$ & $0.30 \pm 0.02$ & $0.06 \pm 0.00$ & $0.74 \pm 0.01$ & $0.17 \pm 0.03$ & $0.40 \pm 0.01$ & $0.20 \pm 0.02$ \\
\hline $\begin{array}{l}\text { Oleuropein aglycon } \\
\text { isomer } 2\end{array}$ & $2.57 \pm 0.01$ & nd & nd & nd & $\mathrm{nq}$ & nd & nd & $1.56 \pm 0.12$ & nd \\
\hline Apigenin & $\mathrm{nq}$ & $0.13 \pm 0.01$ & nq & nd & & $\begin{array}{r}0.61 \pm \\
0.012\end{array}$ & $0.32 \pm 0.03$ & $0.08 \pm 0.01$ & $0.04 \pm 0.01$ \\
\hline Diosmetin & $\mathrm{nq}$ & $0.18 \pm 0.01$ & nd & nd & $0.29 \pm 0.02$ & nd & nd & $0.04 \pm 0.01$ & nd \\
\hline
\end{tabular}

nd: not detected; nq: not quantified (under the limit of quantification).

the polar extract. The reaction mixture was shaken vigorously for $10 \mathrm{~s}$ in a vortex apparatus and then maintained in the dark for $20 \mathrm{~min}$, after which a steady state was reached. The absorbance of the mixture was measured at $515 \mathrm{~nm}$ against a blank solution (without radical). A control sample (without olive leaf extract) was prepared and measured. The RSC toward $\mathrm{DPPH}^{\bullet}$ was expressed as the \% reduction in $\mathrm{DPPH}^{\bullet}$ concentration by the constituents of the oils: $\%$ $\left[\mathrm{DPPH}^{\bullet}\right] \quad \operatorname{red}=100 *\left(1-\left[\mathrm{DPPH}^{\bullet}\right]_{20} /\left[\mathrm{DPPH}^{\bullet}\right]_{0}\right) \quad$ where $\left[\mathrm{DPPH}^{\bullet}\right]_{0}$ and $\left[\mathrm{DPPH}^{\bullet}\right]_{20}$ were the concentrations of 


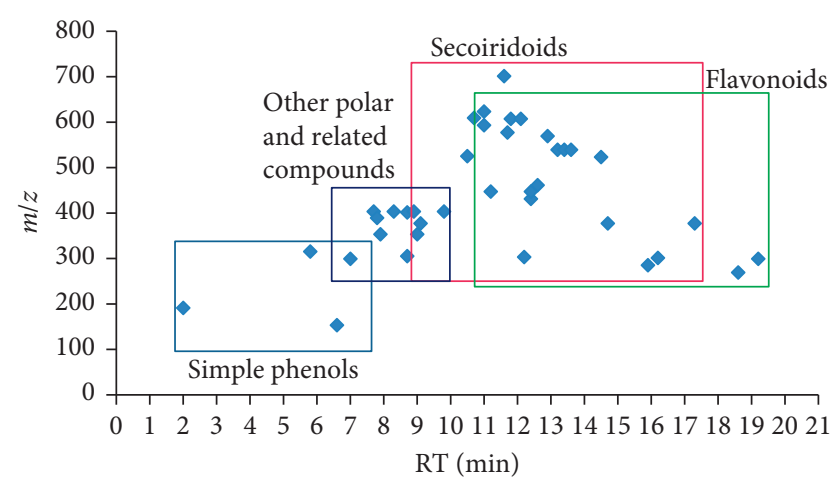

FIgURE 2: Distribution of the identified compounds according to their retention time and $\mathrm{m} / \mathrm{z}$.

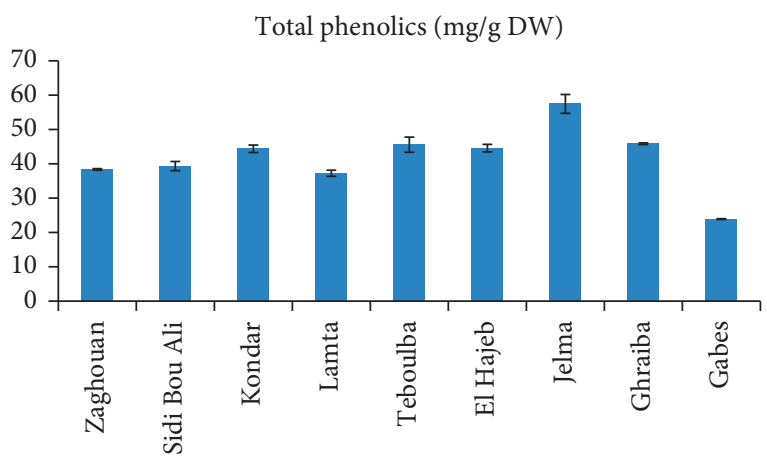

Figure 3: Total phenolic contents in "Chemlali" olive leaf extracts according to the cultivation regions.

$\mathrm{DPPH}^{\bullet}$ in the control sample $(t=0)$ and in the test mixture after the 20-minute reaction, respectively.

2.5. Statistical Analysis. Statistical analysis was performed by means of XLSTAT for Windows. Data are given as means of triplicates. Hierarchical cluster analysis (HCA) was performed using Ward's method based on Euclidean distance.

\section{Results and Discussion}

3.1. HPLC-MS Analysis of the Olive Leaf Extract. The base peak chromatogram (BPC) of "Chemlali" olive leaf extract and the compounds characterized in the negative ion mode are shown in Figure 1. Peak identification was carried out using Target Analysis software (Bruker Daltonics), by comparing both migration time and accurate MS and MS/MS spectral data obtained from olive leaf samples and commercial standards, together with the information previously reported in the literature.

Table 1 summarizes the information about the identified phenolic compounds, in "Chemlali" olive leaf extracts, together with their corresponding retention time, theoretical mass to charge ratio $(\mathrm{m} / \mathrm{z})$, molecular formula, and IT/MS ${ }^{2}$ fragments. A total of 38 compounds could be identified. Three main phenolic groups could be clearly distinguished: phenolic alcohols (hydroxytyrosol, tyrosol, and tyrosol glucoside), flavonoids (luteolin rutinoside, 2 isomers of luteolin glucoside, 2

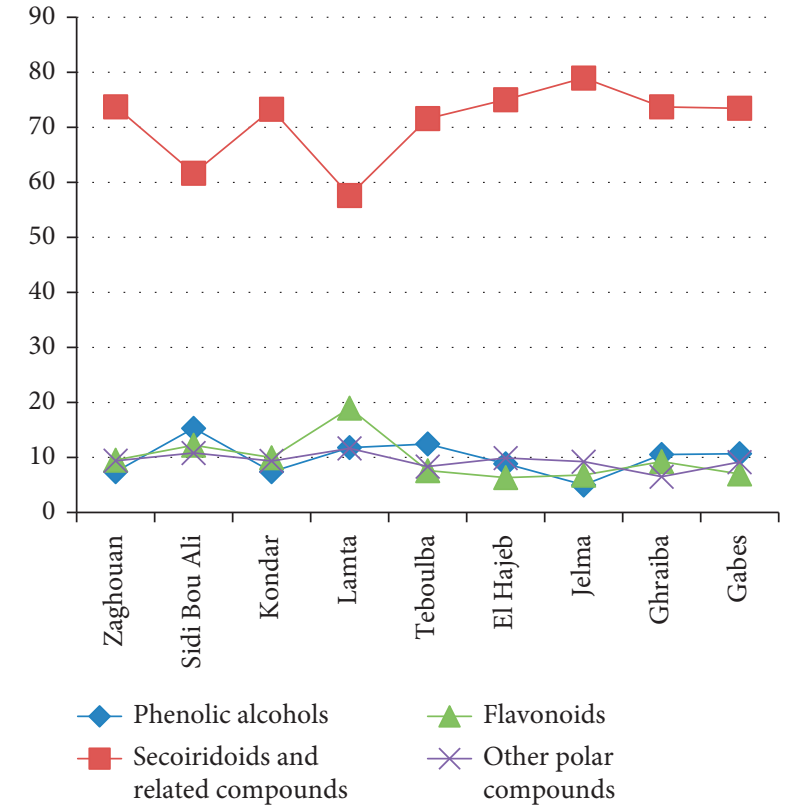

Figure 4: Variation in the distribution of the phenolic compound classes in "Chemlali" olive leaf extracts according to the cultivation regions.

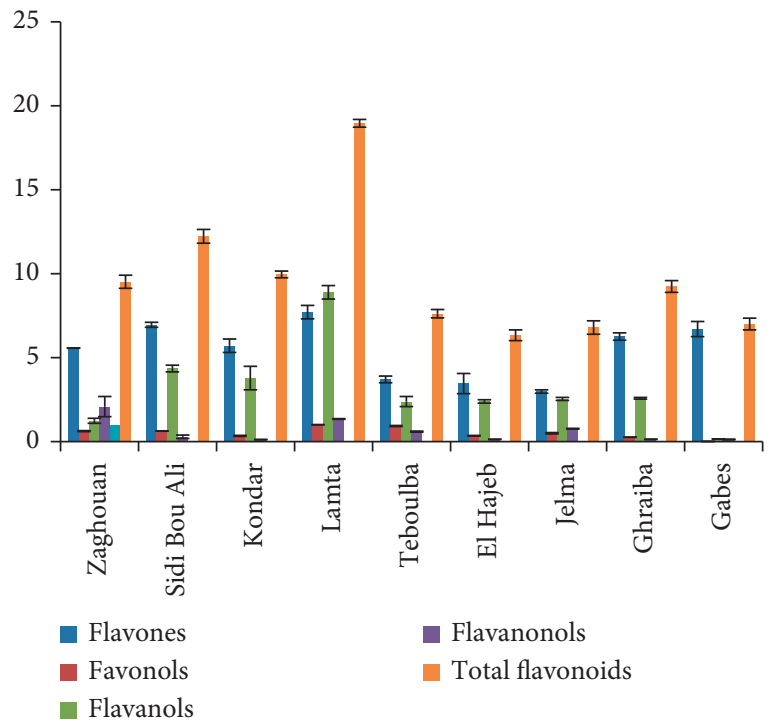

Figure 5: Variation in the distribution of flavonoids in "Chemlali" olive leaf extracts according to the cultivation regions.

isomers of diosmin, apigenin rutinoside, apigenin glucoside, chryseriol glucoside, luteolin, apigenin, rutin, quercetin, gallocatechin, taxifolin, and diosmetin), and various secoiridoids (particularly, oleuropein with 3 isomers, methoxyoleuropein, ligstroside, oleuropein aglycon derivative and related compounds such as elenolic acid glucoside isomers, and secologanoside). Apart from them, other polar compounds were also found; they are quinic acid, caffeoylquinic acid isomers, and benzyl alcohol hexose-pentose. A certain tendency in the elution order of the compounds related to their chemical structure class was observed, appearing in the following order 


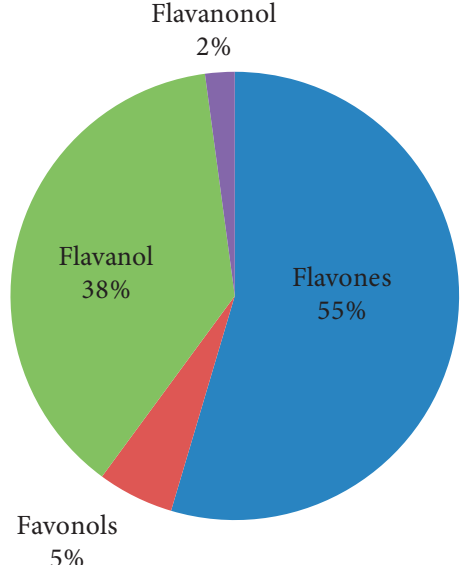

(a)

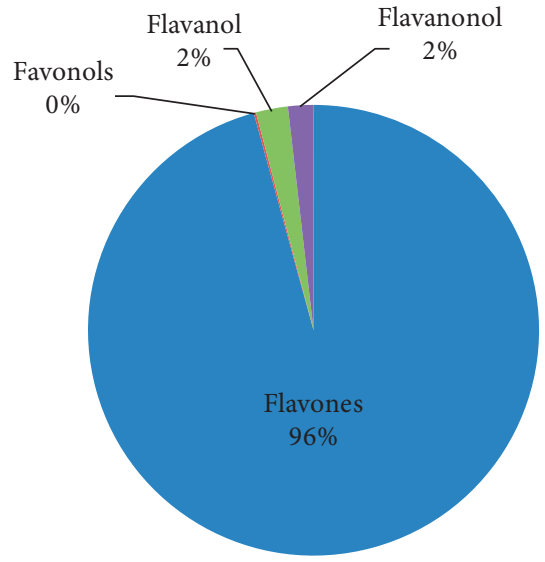

(c)

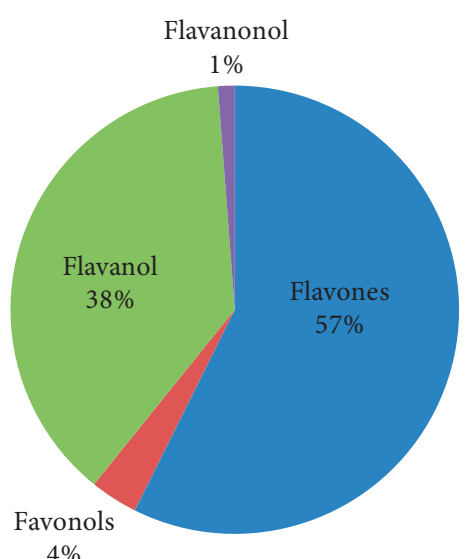

(e)

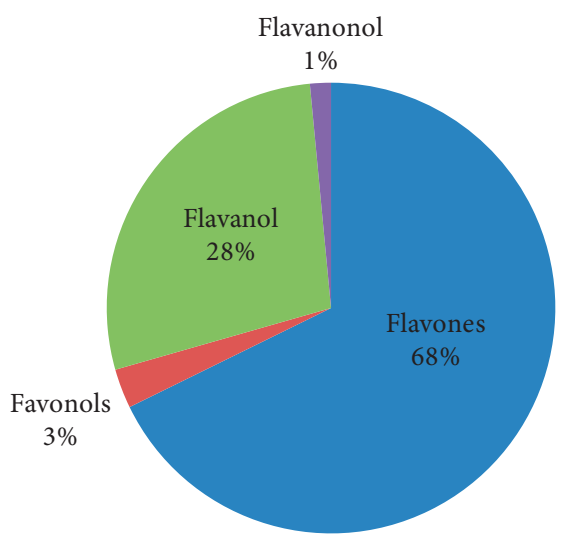

(b)

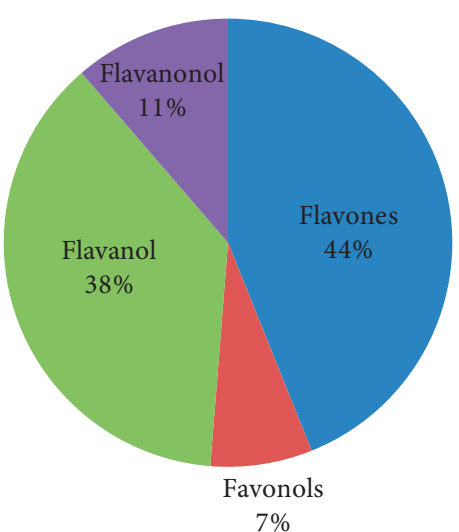

(d)

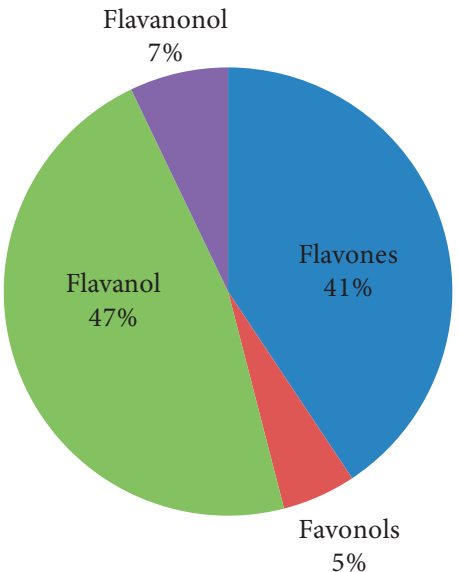

(f)

FIgURE 6: Continued. 


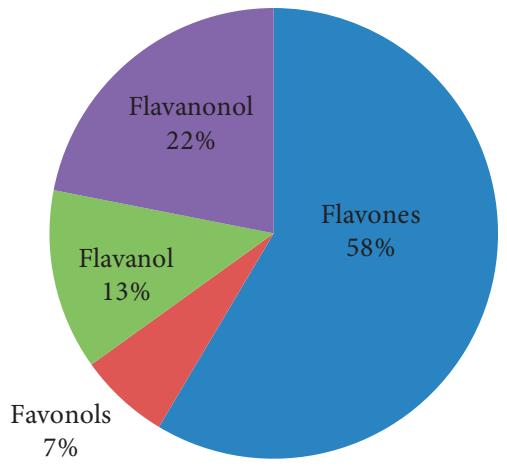

(g)

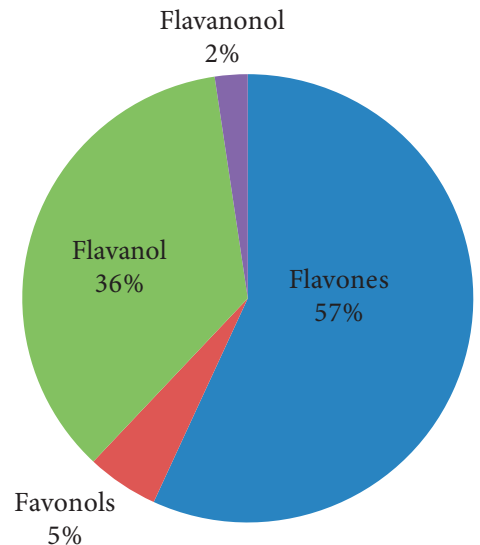

(h)

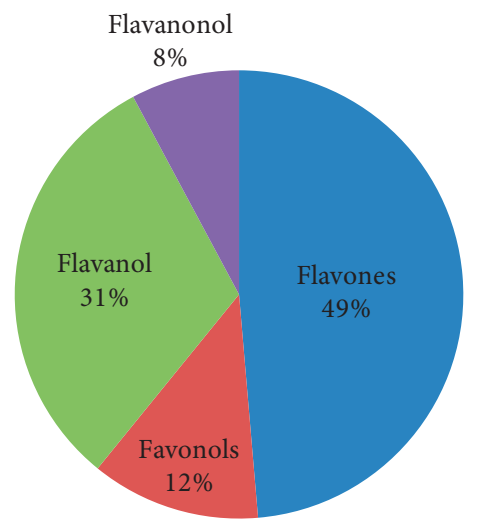

(i)

Figure 6: Flavonoid subclasses distribution. (a) El Hajeb. (b) Ghraiba. (c) Gabes. (d) Jelma. (e) Kondar. (f) Lamta. (g) Zaghouan. (h) Sidi Bou Ali. (i) Teboulba.

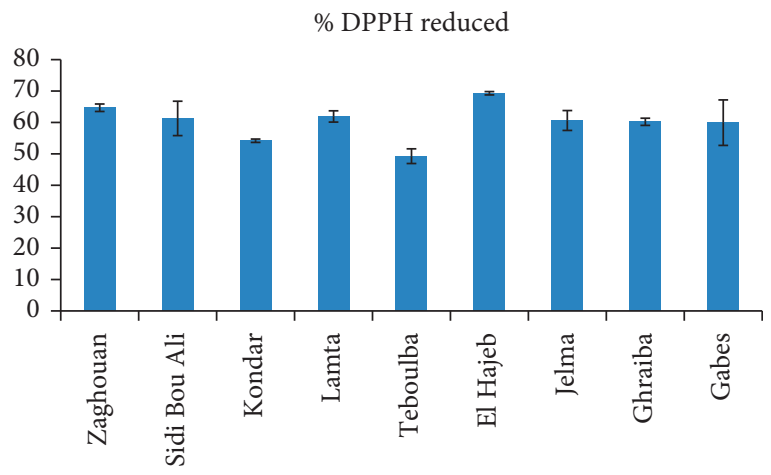

FIGURE 7: Radical-scavenging capacity of olive leaf extracts according to the cultivation regions.

of increasing retention time (RT), and thus hydrophobicity: simple phenols, secoiridoids and related compounds, and flavonoids (Figure 2).

As can be observed in Table 2, some qualitative differences were registered among olive leaf samples from the geographical studied regions. Quantitatively, significant differences were found in a wide number of phenolic

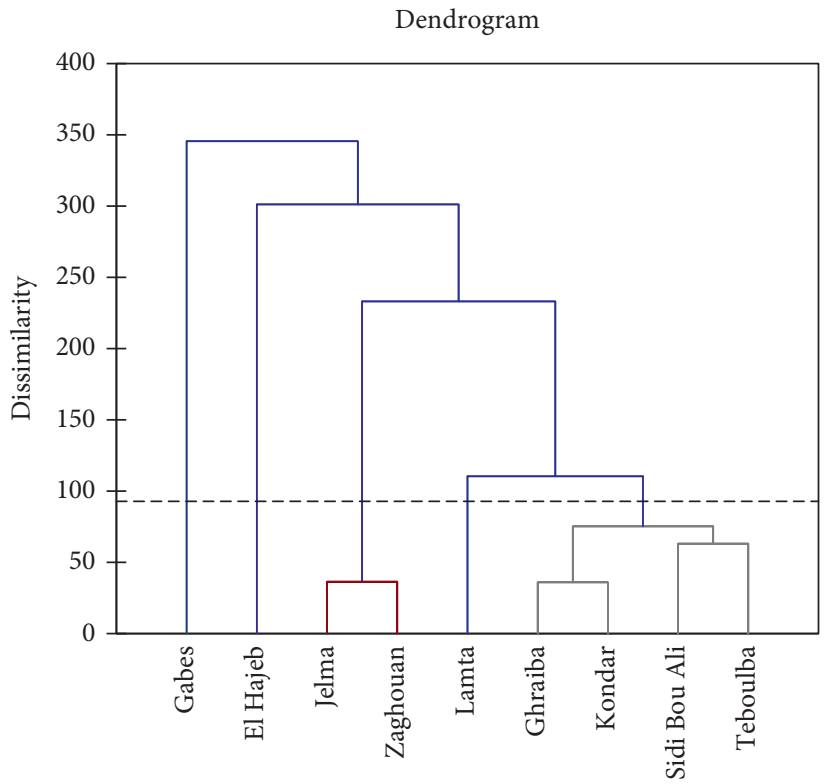

FIGURE 8: Hierarchical cluster analysis dendrogram. Groups: (1) Gabes; (2) Ghraiba, Kondar, Sidi Bou Ali, Teboulba; (3) El Hajeb; (4) Jelma, Zaghouan; (5) Lamta. 


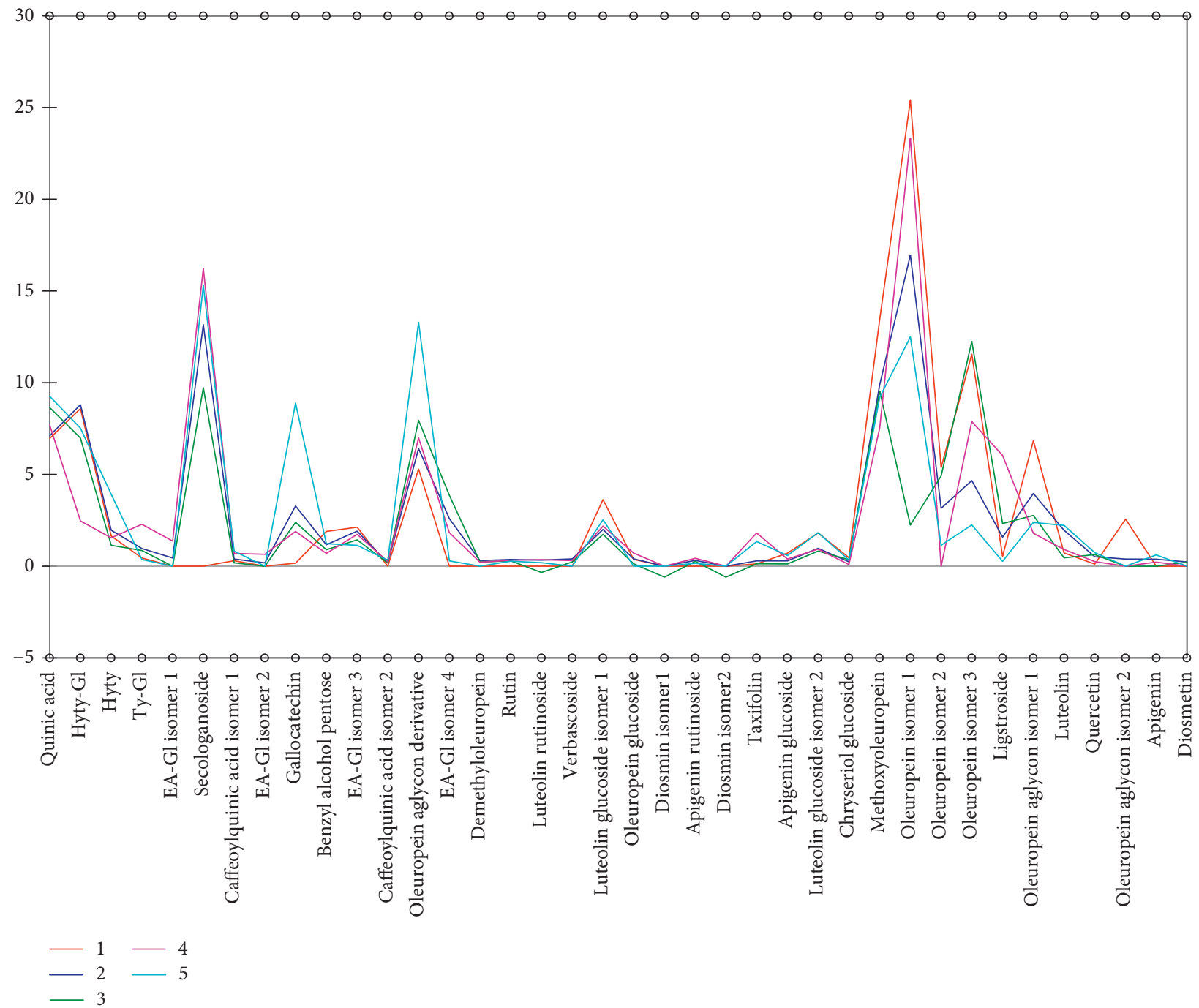

FIGURE 9: HCA groups' profiles according to the phenolic composition. Groups: (1) Gabes; (2) Ghraiba, Kondar, Sidi Bou Ali, Teboulba; (3) El Hajeb; (4) Jelma, Zaghouan; (5) Lamta.

compounds according to the geographical origin of the samples. Our results are in agreement with those reported in literature. In deed comparing Tunisian cultivars located in southern and northern Tunisia, significant differences were observed for phenolic composition as well as antioxidant activity where higher levels were registered for samples from the north [29].

Bilgin and Şahin [28] demonstrated that total phenolic content and extract yield varied significantly among Turkish olive cultivars from six sites in Anatolia. The authors observed that the total phenolic contents in olive leaves decreased as the geographical altitude decreases [28]. In another study on Greek olive cultivars, leaves collected from three different locations showed differences in total phenolic contents and antioxidant activity [27]. Similarly, the geographical zone has influenced the phenolic composition of Arbequina cultivar samples collected from six regions in Spain [30]. Using hierarchical cluster analysis, the latter study showed high similarities between the olive leaf samples from Cordoba and Navarra and both samples from Mallorca, respectively.
In our study, significant differences were observed for total phenolic contents in "Chemlali" olive leaf extracts from different regions (Figure 3). These differences could be explained by the most marked variation that was observed for flavonoids and secoiridoids and related compounds as well as for phenolic alcohols classes especially for the leaves collected from Lamta region. These classes presented amounts that reached 18, 78 and 15\% for Lamta, Jelma, and Sidi Bou Ali, respectively. Furthermore, we can observe that secoiridoids' tendency was the inverse of that of flavonoids (Figure 4).

Being the major one among the identified compounds, oleuropein amounts varied significantly among olive leaf samples. The registered values were between 15.8 and $42.25 \%$ for samples from Gabes and Lamta regions, respectively.

Considering the subclasses of flavonoids, the most pronounced variation among samples from different regions was registered for flavones and flavanols. Flavones presented the highest percentage among the rest of flavonoids followed by flavanols. Among analyzed samples, olive leaves from 
Gabes showed the highest percentage in flavones, whereas leaves from Lamta showed the highest levels in flavanols presented by gallocatechin (Figures 5 and 6).

Radical-scavenging activity is very important, due to the deleterious role of free radicals in foods and in biological systems. This test is a standard assay in antioxidant activity studies and offers a rapid technique for screening the radicalscavenging activity of specific compounds. The stable free $\mathrm{DPPH}$ radical is a useful reagent to investigate the scavenger properties of phenolics [34]. The radical-scavenging capacity values varied significantly between studied samples: the leaves from Zaghouan presented the highest radicalscavenging capacity, whilst leaves from Teboulba showed a radical-scavenging capacity of $49 \%$ (Figure 7 ).

3.2. Chemometrics. Data clustering is a common technique for statistical data analysis, which is used in many fields. It is known as the classification of objects into groups (clusters), so that the data in each subset share some common trait-often proximity according to some defined distance measure [35]. The hierarchical analysis is a kind of very important clustering methods. It is an unsupervised technique that examines the interpoint distances between all of the samples and represents that information in the form of a two dimensional plot called a hierarchical tree or dendrogram.

In our study, an overall cluster analysis based on the determined metabolites and radical-scavenging capacity was performed to study the general differences among samples. To display the similarities between olive leaf samples from different provenance, a dendrogram was produced by applying a hierarchical clustering algorithm to the data.

As can be seen in Figure 8, there is a clear separation among the clusters established for different samples. Applying Ward's method based on Euclidean distance, olive leaf samples could be gathered into five different groups with respect to their phenolic composition: the first presented by Gabes region; the second by Ghraiba, Kondar, Sidi Bou Ali, and Teboulba; and the third by El Hajeb. The fourth group is composed by Jelma and Zaghouan and the fifth by Lamta.

It is useful to mention that HCA could be successfully applied for the classification and evaluation of the regional growing effects on the specification of the olive leaves based on their phenolic profile. In Figure 9, the profiles of the distinguished clusters or groups are illustrated. As can be seen, the leaves from Lamta region located in the coastal center of Tunisia are richer in gallocatechin and oleuropein aglycone derivative. Groups 1 and 4 presented the leaves richer in oleuropein isomer 1. Moreover, leaves from Gabes (group 1) located in the coastal south of Tunisia showed their richness in oleuropein aglycone.

These results are important since they may be useful for further researches and give an insight into the behavior of phenolic compounds in olive leaves from different environments. Such compounds have shown to be sensible to the edaphoclimatic variation between the considered regions of cultivation of "Chemlali" cultivar.

\section{Conflicts of Interest}

The authors declare no conflicts of interest.

\section{Acknowledgments}

The authors are grateful to the Tunisian Ministry of Higher Education and Scientific Research, the Spanish Ministry of Economy and Competitiveness (MINECO) (AGL201567995-C3-2-R), and the Andalusian Regional Government Council (P11-CTS-7625).

\section{Supplementary Materials}

Localization of the olive leaves sampling regions. (Supplementary Materials)

\section{References}

[1] B. Dimitrios, "Sources of natural phenolic antioxidants," Trends in Food Science \& Technology, vol. 17, no. 9, pp. 505-512, 2006.

[2] D. Komes, A. Belščak-Cvitanović, D. Horžić, G. Rusak, S. Likić, and M. Berendika, "Phenolic composition and antioxidant properties of some traditionally used medicinal plants affected by the extraction time and hydrolysis," Phytochemical Analysis, vol. 22, no. 2, pp. 172-180, 2011.

[3] M. S. Butler, "The role of natural product chemistry in drug discovery," Journal of Natural Products, vol. 67, no. 12, pp. 2141-2153, 2004.

[4] R. Gyawali and S. A. Ibrahim, "Natural products as antimicrobial agents," Food Control, vol. 46, pp. 412-429, 2014.

[5] D. J. Newman and G. M. Cragg, "Natural products as sources of new drugs from 1981 to 2014," Journal of Natural Products, vol. 79, no. 3, pp. 629-661, 2016.

[6] G. M. Cragg and D. J. Newman, "Natural products : a continuing source of novel drug leads," Biochimica et Biophysica Acta, vol. 1830, no. 6, pp. 3670-3695, 2013.

[7] L. M. Blair and J. Sperry, "Natural products containing a nitrogen-nitrogen bond," Journal of Natural Products, vol. 76, no. 4, pp. 794-812, 2013.

[8] J.-H. Park, J.-H. Jung, J.-Y. Yang, and H.-S. Kim, “Olive leaf down-regulates the oxidative stress and immune dysregulation in streptozotocin-induced diabetic mice," Nutrition Research, vol. 33, no. 11, pp. 942-951, 2013.

[9] N. Xynos, G. Papaefstathiou, M. Psychis, A. Argyropoulou, N. Aligiannis, and A.-L. Skaltsounis, "Development of a green extraction procedure with super/subcritical fluids to produce extracts enriched in oleuropein from olive leaves," Journal of Supercritical Fluids, vol. 67, pp. 89-93, 2012.

[10] M. Ben Salah, H. Abdelmelek, and M. Abderraba, "Study of phenolic composition and biological activities assessment of olive leaves from different varieties grown in Tunisia," $M e$ dicinal Chemistry, vol. 2, no. 5, pp. 107-111, 2012.

[11] J. E. Hayes, P. Allen, N. Brunton, M. N. O'Grady, and J. P. Kerry, "Phenolic composition and in vitro antioxidant capacity of four commercial phytochemical products: Olive leaf extract (Olea europaea L.), lutein, sesamol and ellagic acid," Food Chemistry, vol. 126, no. 3, pp. 948-955, 2011.

[12] K. Kiritsakis, M. G. Kontominas, C. Kontogiorgis, D. Hadjipavlou-Litina, A. Moustakas, and A. Kiritsakis, "Composition and antioxidant activity of olive leaf extracts from Greek olive cultivars," Journal of the American Oil Chemists' Society, vol. 87, no. 4, pp. 369-376, 2009. 
[13] O.-H. Lee, B.-Y. Lee, J. Lee et al., “Assessment of phenolicsenriched extract and fractions of olive leaves and their antioxidant activities," Bioresource Technology, vol. 100, no. 23, pp. 6107-6113, 2009.

[14] K. Hassanzadeh, K. Akhtari, H. Hassanzadeh, S. A. Zarei, N. Fakhraei, and K. Hassanzadeh, "The role of structural C-H compared with phenolic $\mathrm{OH}$ sites on the antioxidant activity of oleuropein and its derivatives as a great non-flavonoid family of the olive components: a DFT study," Food Chemistry, vol. 164, pp. 251-258, 2014.

[15] D. Raederstorff, "Antioxidant activity of olive polyphenols in humans: a review," International Journal for Vitamin and Nutrition Research, vol. 79, no. 3, pp. 152-165, 2009.

[16] A. M. Al-attar and N. A. Shawush, "Physiological investigations on the effect of olive and rosemary leaves extracts in male rats exposed to thioacetamide," Saudi Journal of Biological Sciences, vol. 21, no. 5, pp. 473-480, 2014.

[17] A. Kaeidi, S. Esmaeili-Mahani, V. Sheibani et al., "Olive (Olea europaea L.) leaf extract attenuates early diabetic neuropathic pain through prevention of high glucose-induced apoptosis: in vitro and in vivo studies," Journal of Ethnopharmacology, vol. 136, no. 1, pp. 188-196, 2011.

[18] F. Brahmi, G. Flamini, M. Issaoui et al., "Chemical composition and biological activities of volatile fractions from three Tunisian cultivars of olive leaves," Medicinal Chemistry Research, vol. 21, no. 10, pp. 2863-2872, 2011.

[19] R. Fabiani, P. Rosignoli, A. De Bartolomeo et al., "Oxidative DNA damage is prevented by extracts of olive oil, hydroxytyrosol, and other olive phenolic compounds in human blood mononuclear cells and HL60 cells," Journal of Nutrition, vol. 138, no. 8, pp. 1411-1416, 2008.

[20] A. Taamalli, D. Arráez-Román, E. Barrajón-Catalán et al., "Use of advanced techniques for the extraction of phenolic compounds from Tunisian olive leaves: phenolic composition and cytotoxicity against human breast cancer cells," Food and Chemical Toxicology, vol. 50, no. 6, pp. 1817-1825, 2012.

[21] E. Barrajón-Catalán, A. Taamalli, R. Quirantes-Piné et al., "Differential metabolomic analysis of the potential antiproliferative mechanism of olive leaf extract on the JIMT-1 breast cancer cell line," Journal of Pharmaceutical and Biomedical Analysis, vol. 105, pp. 156-162, 2015.

[22] L. Abaza, T. P. N. Talorete, P. Yamada, Y. Kurita, M. Zarrouk, and H. Isoda, "Induction of growth inhibition and differentiation of human leukemia HL-60 cells by a Tunisian Gerboui olive leaf extract," Bioscience, Biotechnology, and Biochemistry, vol. 71, no. 5, pp. 1306-1312, 2007.

[23] J. F. Ayala-Zavala, V. Vega-Vega, C. Rosas-Domínguez et al., "Agro-industrial potential of exotic fruit byproducts as a source of food additives," Food Research International, vol. 44, no. 7, pp. 1866-1874, 2011.

[24] A. Taamalli, D. Arráez-Román, M. Zarrouk, J. Valverde, A. Segura-Carretero, and A. Fernández-Gutiérrez, "The occurrence and bioactivity of polyphenols in Tunisian olive products and by-products: a review," Journal of Food Science, vol. 77, no. 4, pp. R83-R92, 2012.

[25] S. N. El and S. Karakaya, "Olive tree (Olea europaea) leaves potential beneficial effects on human health," Nutrition Reviews, vol. 67, no. 11, pp. 632-638, 2009.

[26] N. Talhaoui, A. Taamalli, A. M. Gómez-Caravaca, A. Fernández-Gutiérrez, and A. Segura-Carretero, "Phenolic compounds in olive leaves: analytical determination, biotic and abiotic influence, and health benefits," Food Research International, vol. 77, pp. 92-108, 2015.
[27] E. Giannakopoulou, G. Mitsopoulos, M. Hagidimitriou, V. Papageorgiou, and M. Komaitis, "Influence of cultivar, harvesting season and geographical origin on phenolic content in leaves of Greek olive cultivars," Acta Horticulturae, vol. 924, pp. 437-444, 2011.

[28] M. Bilgin and S. Şahin, "Effects of geographical origin and extraction methods on total phenolic yield of olive tree (Olea europaea) leaves," Journal of the Taiwan Institute of Chemical Engineers, vol. 44, no. 1, pp. 8-12, 2013.

[29] F. Brahmi, B. Mechri, M. Dhibi, and M. Hammami, "Variation in antioxidant activity and phenolic content in different organs of two Tunisian cultivars of Olea europaea L.," Acta Physiologiae Plantarum, vol. 36, no. 1, pp. 169-178, 2013.

[30] R. Japón-Lujan, J. Ruiz-Jiménez, and M. D. L. de Castro, "Discrimination and classification of olive tree varieties and cultivation zones by biophenol contents," Journal of Agricultural and Food Chemistry, vol. 54, no. 26, pp. 9706-9712, 2006.

[31] L. Abaza, N. Ben Youssef, H. Manai, F. M. Haddada, K. Methenni, and M. Zarrouk, "Chétoui olive leaf extracts: influence of the solvent type on phenolics and antioxidant activities," Grasas y Aceites, vol. 62, no. 1, pp. 96-104, 2007.

[32] A. Taamalli, D. Arráez-Román, E. Ibañez, M. Zarrouk, A. Segura-Carretero, and A. Fernández-Gutiérrez, "Optimization of microwave-assisted extraction for the characterization of olive leaf phenolic compounds by using HPLC-ESITOF-MS/IT-MS2," Journal of Agricultural and Food Chemistry, vol. 60, no. 3, pp. 791-798, 2012.

[33] G. Kalantzakis, G. Blekas, K. Pegklidou, and D. Boskou, "Stability and radical-scavenging activity of heated olive oil and other vegetable oils," European Journal of Lipid Science and Technology, vol. 108, no. 4, pp. 329-335, 2006.

[34] İ. Gülçin, "Antioxidant activity of food constituents: an overview," Archives of Toxicology, vol. 86, no. 3, pp. 345-391, 2012.

[35] Z. Piravi-Vanak, J. B. Ghasemi, M. Ghavami, H. Ezzatpanah, and E. Zolfonoun, "The influence of growing region on fatty acids and sterol composition of Iranian olive oils by unsupervised clustering methods," Journal of the American Oil Chemists' Society, vol. 89, no. 3, pp. 371-378, 2012. 

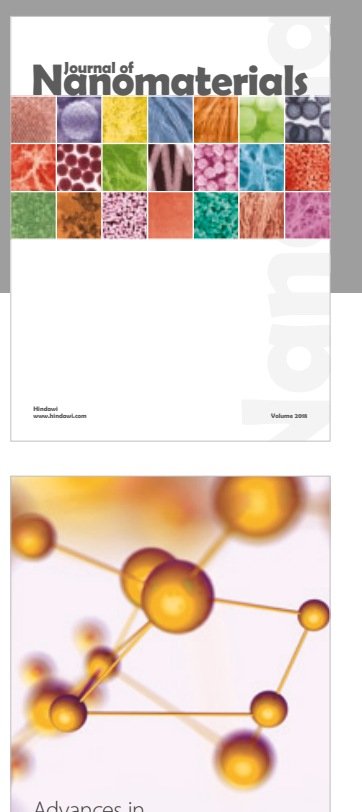

Physical Chemistry
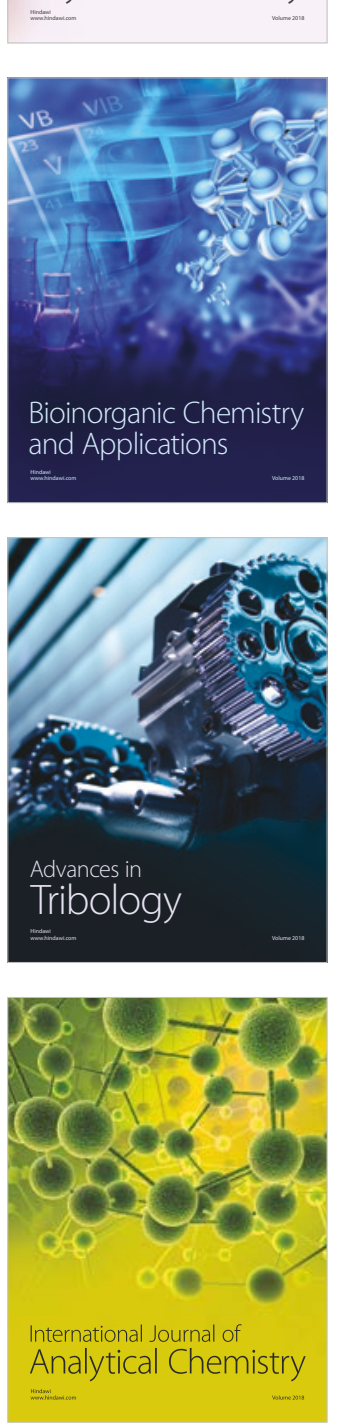

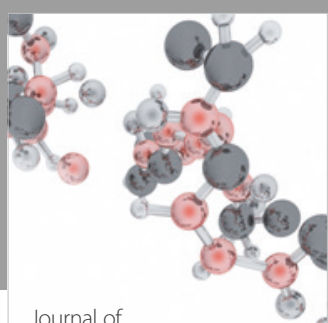

Analytical Methods

in Chemistry

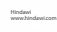

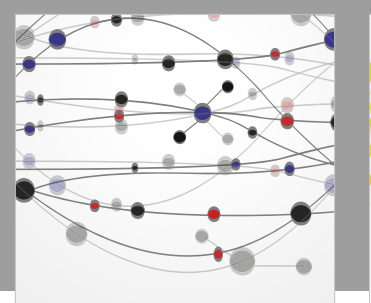

The Scientific World Journal

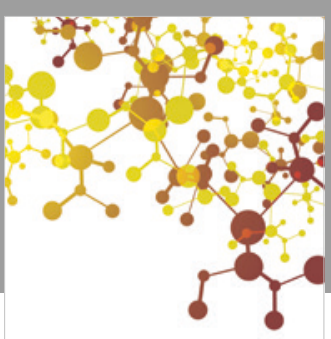

Journal of

Applied Chemistry
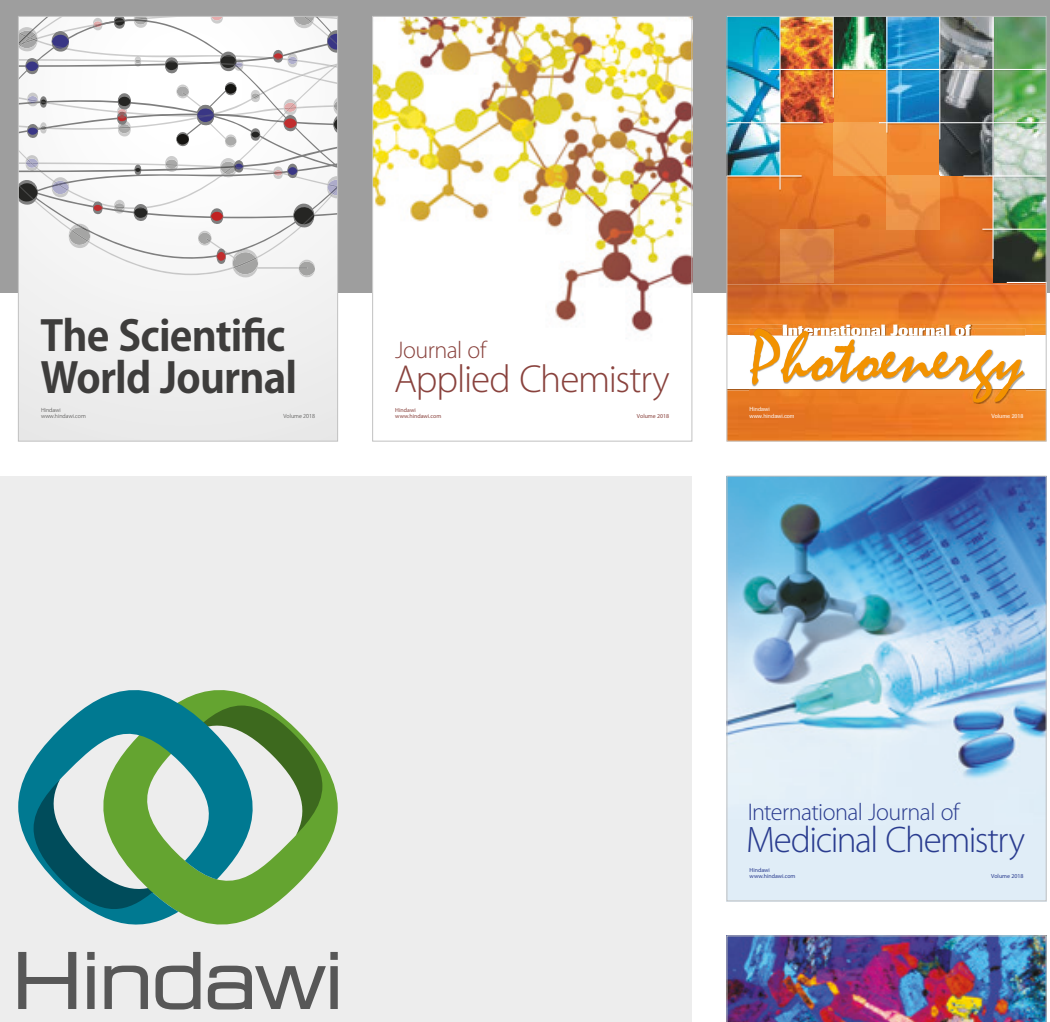

Submit your manuscripts at

www.hindawi.com
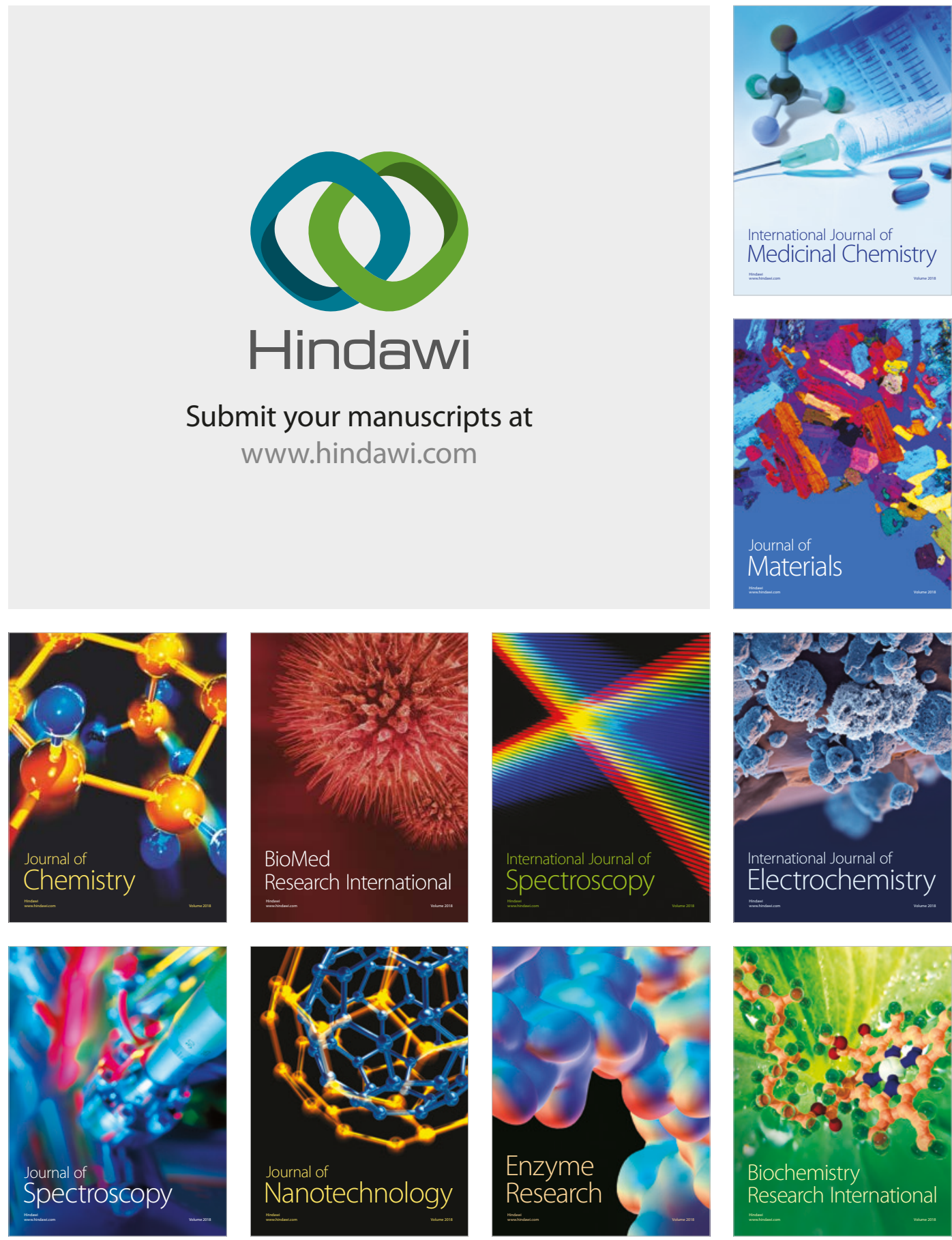
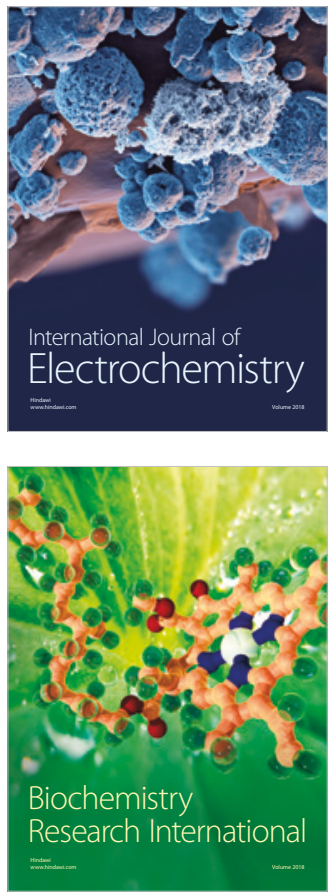